\title{
Convenient Synthesis of Some Novel 4-Benzyl-1(2H)-Phthalazinone Derivatives of expected anticancer activity
}

\author{
Samir M. El Rayes ${ }^{1}$, Ibrahim A. I. Ali ${ }^{1}$, Hamdy A. Soliman ${ }^{1}$, Sara M. Emam ${ }^{2}$ \\ ${ }^{1}$ Department of Chemistry, Faculty of Science, Suez Canal University, Ismailia, \\ Egypt \\ ${ }^{2}$ Micro-analytical and Toxicology Research Unit \& Central Lab, Faculty of \\ Science, Suez Canal University, Ismailia, Egypt
}

\begin{abstract}
Series of new synthesized biologically active phthalazinone derivatives were obtained. Starting from the amino acid methyl esters of 4-benzyl-1(2H)phthalazinone 2a,b which were synthesized from the aceto hydrazide of 4-benzyl1(2H)-phthalazinone 1 via azide coupling method. The hydrazides 3a,b were prepared from hydrazinolysis of corresponding esters 2a,b. $\mathrm{N}$-substituted-2-(4Benzyl-1-oxo-1H-phthalazin-2-yl)-methyl-acetamide 4a-f and the dipeptides methyl \{2-[2-(4-Benzyl-1-oxo-1H-phthalazin-2-yl)-acetylamino]-acetylamino $\}$ alkanoates 6a-c were obtained by the reaction of corresponding hydrazide 3a with amines and amino acid esters respectively via azide coupling method.

Similarly; $N$ - substituted -3-[2-(4-Benzyl-1-oxo-1H-phthalazin-2-yl)-acetyl amino] propionamide 5a-f and the dipeptides methyl\{3-[2-(4-Benzyl-1-oxo-1Hphthalazin-2-yl)-acetylamino]-propionylamino alkanoates 7a-c were obtained by the reaction of corresponding hydrazide $3 \mathbf{b}$ with amines and amino acid esters respectively via azide coupling method
\end{abstract}

Keywords: Chemoselective, phthalazinone, azide, amines, amino acids, dipeptide 


\section{Introduction}

Cancer is one of the most difficult diseases to treat and it is a major disease responsible for deaths worldwide, it can be considered as one of the foremost health problems ${ }^{1}$. Therefore, anticancer drugs research is never ending to obtain lower toxicity and more selectivity products towards tumor cells. It is an urgent need to give much attention to update and modify drug leads from the point of view of medicinal chemistry and drug design to fulfill more potent and effective therapies. Recently, Our research group focused their efforts on searching for new anticancer drugs ${ }^{2,3}$.

phthalazinone derivatives have found application in clinical medicine due to their pronounced antihypertensive properties ${ }^{4}$, cardiotonic $^{5,6}$, anticonvulsant ${ }^{7,8}$, antidiabetic $^{9,10}$, antithrombotic ${ }^{11}$, antimicrobial ${ }^{12,13}$ antipyretic, analgesic, antitumor $^{14-17}$ and cytotoxic ${ }^{18}$.

A series of 4-substituted-2H-phthalazin-1-ones have been investigated as potent orally bioavailable PARP (poly (adenosine diphosphate-ribose) polymerases) inhibitor ${ }^{19-26}$ Olaparib I, MRU-868 II and KU0058958 III are the most interesting PARP inhibitors based on the 4-substituted-2H-phthalazin- 1-one scaffold and compound IV inhibits aurora-A kinase based upon a 4-(pyrazole-3ylamino)phenyl-2H-phthalazin-1-one scaffold and has in vitro cytotoxic activity against HCT116 colon cell line ${ }^{27}$, these commercial phthalazinone derivatives are shown in figure 1 . 
<smiles>O=C(c1cccc(F)c1)N1CCN(C(=O)C2CC2)CC1</smiles>

Olaparib I<smiles>O=C1CCC(=O)N1c1cc(Cc2n[nH]c(=O)c3ccccc23)ccc1F</smiles>

MRU-868 II<smiles>O=C(c1cccc(F)c1)N1CCNCC1</smiles>

KU0058958 III<smiles>CC1CC(Nc2nn(CC(=O)c3ccccc3)c(=O)c3ccccc23)=NN1</smiles>

4-(5-Methyl-4,5-dihydro-1 $H$-pyrazol-3-ylamino)-2-(2-oxo-2phenyl-ethyl)-2 $H$-phthalazin-1-one

IV

Figure 1: Some phthalazinone anticancer drugs

We will present new compound designs from N-substituted phthalazin-1-one derivatives based on the 4- benzylphthalazin-1-one scaffold in an attempt to obtain a potent anticancer agent.

\section{Discussion}

Our research group reported early that ${ }^{28-31}$, how we can control on chemoselective alkylation in both amides and thioamides. As extension of these studies, we achieve N-alkylation of 4-Benzyl-2H-phthalazin-1-one to the corresponding methyl-4-Benzyl-1-oxo-1H-phthalazin-2-yl-acetate to the corresponding (4Benzyl-1-oxo-1H-phthalazin-2-yl)-acetic acid hydrazide (1) which used as a precursor for the preparation of our targeted newly phthalazinone molecules. 
The alkylation reaction proceeds selectively on $\mathrm{N}$ atom not at $\mathrm{O}$ atom or even in competition reaction at both atoms. We can explain that depending on their behavior towards electrophiles according to reaction control points as basisty and neucleophilicity of both $\mathrm{N}$ and $\mathrm{O}$ atoms. The product was methyl-4-Benzyl-1-oxo$1 \mathrm{H}$-phthalazin-2-yl-acetate prove that the $\mathrm{N}$ atom in present system is stronger neucleophile more than Oxygen i.e this reaction is new evidence for basis of chemoselective reactivity of heterocyclic amides towards electrophiles scheme1. The chemoselectivity alkylation proved that occur on the $\mathrm{N}$ - atom not the $\mathrm{O}$ isomer so this reaction is $\mathrm{N}$ - regioselective and this can be dedicated by the structure characterization using ${ }^{1} \mathrm{H}$ and ${ }^{13} \mathrm{C}$ - NMR spectroscopy.

General procedure for 4-Benzyl-1-oxo-1H-phthalazin-2-yl)-acetic acid hydrazide (1)

The phthalazine aceto hydrazide $\mathbf{1}$ was prepared by four steps procedure as outlined in scheme 1 starting from the fusion of phthalic anhydride with phenyl acetic acid in the presence of fused sodium acetate in sand bath from 230 to $240^{\circ} \mathrm{C}$ yielding 3-benzal phthalide ${ }^{32}$, which reacted with hydrazine hydrate in boiling ethanol to give the benzyl phthalazinone derivative ${ }^{33}$. The benzyl phthalizinone derivative was refluxed with ethyl chloro acetate in the presence of anhydrous $\mathrm{K}_{2} \mathrm{CO}_{3}$ in boiling DMF/ acetone (1:1) led to the oxophthalazinyl acetate compound that was converted to the desired acetohydrazide $\mathbf{1}$ by reaction with hydrazine hydrate in boiling ethanol ${ }^{34}$. 


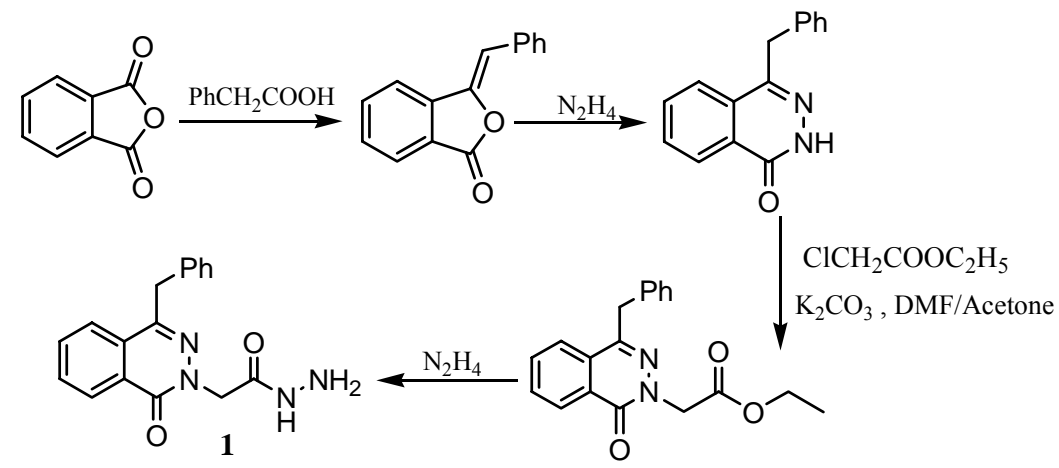

Scheme (1): Synthesis of hydrazide 1

According to the azide coupling method ${ }^{35}$, the aceto hydrazide derivative $\mathbf{1}$ was stirred with sodium nitrite and hydrochloric acid mixture at $-5^{\circ} \mathrm{C}$ forming azide molecule that in ethyl acetate solution react with amino acid ester hydrochloride in the presence of tri ethyl amine afforded the N-substituted amino acid methyl esters of 4-benzyl-1(2H)-phthalazinone 2a,b (Gly and $\beta$-Ala) in good yield in scheme 2.<smiles></smiles>

Scheme 2: Preparation of amino acid ester compounds 2a,b and their corresponding hydrazides 3a,b

The glycine methyl ester of 4-benzyl-1(2H)-phthalazinone 2a has the ${ }^{1} \mathrm{H}$ - NMR spectrum of characteristic signals at $3.64,4.2, \underline{4}$ and $4.9 \mathrm{ppm}$ for $\mathrm{O}-\mathrm{CH}_{3}, \mathrm{~N}-\underline{\mathrm{CH}}_{2}$, $\mathrm{CH}_{2} \mathrm{CO}$ and $\mathrm{CH} 2-\mathrm{Ph}$ groups respectively and the ${ }^{13} \mathrm{C}$ - NMR spectrum has signals at $159.78,167.72169 .99$ for $3 \mathrm{C}=\mathrm{O}$ groups $54.8,52.27,41.29$ and $38.91 \mathrm{ppm}, \mathrm{O}-$ $\mathrm{CH}_{3}, \mathrm{~N}-\mathrm{CH}_{2}, \mathrm{CH}_{2} \mathrm{CO}$ and $\mathrm{CH}_{2}-\mathrm{Ph}$ groups respectively . 
$\mathrm{N}$-substituted amino acid methyl esters of 4-benzyl-1(2H)-phthalazinone 2a,b were considered key intermediates for our chemical structure modification of phthalazinone nucleus. The esters 2a,b underwent hydrazinolysis via reflux with hydrazine hydrate in ethanol forming corresponding hydrazides 3a,b.

Under azide coupling condition, the 2-(4-Benzyl-1-oxo-1H-phthalazin-2-yl)-Nhydrazinocarbonylmethyl-acetamide 3a was treated with a mixture of sodium nitrite and $\mathrm{HCl}$ solution to give its corresponding azide solution which further treatment with different amines like n-benzyl, n-propyl, n-butyl, cyclohexyl, tetra decyl and allyl amines gave corresponding $N$ - substituted -2-(4-Benzyl-1-oxo-1Hphthalazin-2-yl)- methyl-acetamides 4a-f.

Similarly, starting from the 2-(4-Benzyl-1-oxo-1H-phthalazin-2-yl)-N-(2hydrazinocarbonyl-ethyl)-acetamide $\mathbf{3 b}$ under same azide coupling condition, $\mathrm{N}$ substituted -3-[2-(4-Benzyl-1-oxo-1H-phthalazin-2-yl)-acetyl amino]propionamide 5a-f were obtained as shown in scheme 3 . 


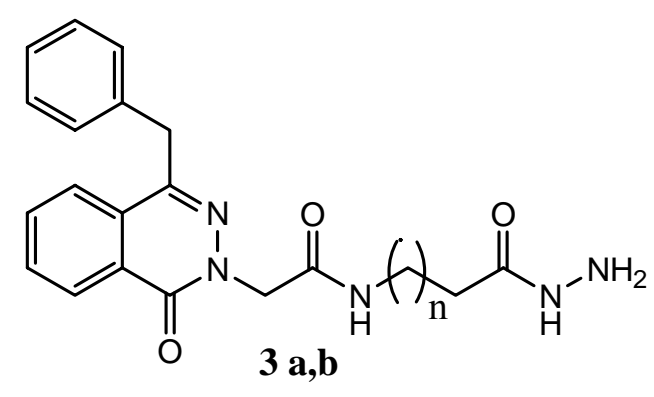

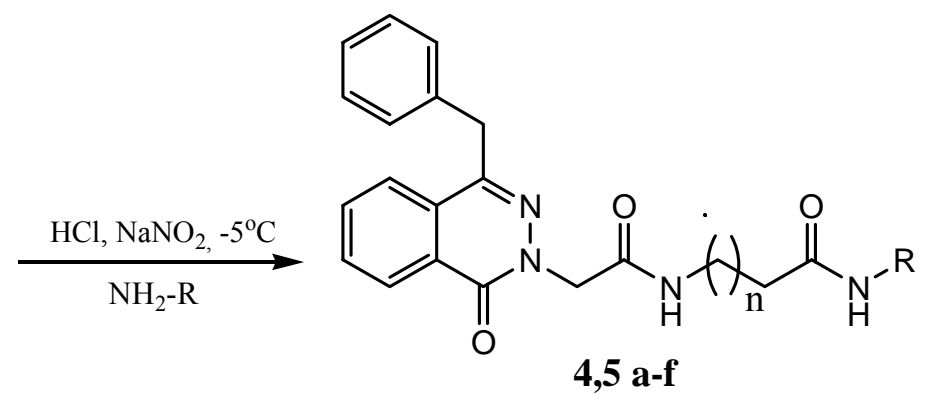

\begin{tabular}{|c|c|c|c|c|c|}
\hline 4 & $\mathbf{n}$ & $\mathbf{R}$ & 5 & $\mathbf{n}$ & $\mathbf{R}$ \\
\hline $\mathbf{a}$ & $\mathbf{0}$ & 10 & $\mathbf{a}$ & 1 & 10 \\
\hline b & $\mathbf{0}$ & $\mathrm{CH}_{3}-\mathrm{CH}_{2}-\mathrm{CH}_{2}$ & b & 1 & $\mathrm{CH}_{3}-\mathrm{CH}_{2}-\mathrm{CH}_{2}$ \\
\hline C & $\mathbf{0}$ & $\begin{array}{c}\mathrm{CH}_{3}-\mathrm{CH}_{2}-\mathrm{CH}_{2}- \\
\mathrm{CH}_{2}\end{array}$ & C & 1 & $\begin{array}{c}\mathrm{CH}_{3}-\mathrm{CH}_{2}-\mathrm{CH}_{2}- \\
\mathrm{CH}_{2}\end{array}$ \\
\hline d & $\mathbf{0}$ & & d & 1 & \\
\hline e & $\mathbf{0}$ & $\mathrm{CH}_{3^{-}}\left(\mathrm{CH}_{2}\right)_{14}$ & e & 1 & $\mathrm{CH}_{3^{-}}\left(\mathrm{CH}_{2}\right)_{14}$ \\
\hline $\mathbf{f}$ & 0 & & $\mathbf{f}$ & 1 & \\
\hline
\end{tabular}

Scheme 3: Synthesis of $N$-substituted-2-(4-Benzyl-1-oxo-1H-phthalazin-2-yl)amides 4,5a-f

The azide form of 1-oxo-1H-phthalazin-2-yl)-N-hydrazino carbonyl methylacetamide 3a was coupled with different amino acid methyl esters of glycine, $\beta$ alanine and valine affording (dipeptides) methyl-2-[2-(4-Benzyl-1-oxo-1Hphthalazin-2-yl)-acetylamino]-acetylamino-alkanoates in reasonable yield 6a-c. Under the same condition, methyl-3-[2-(4-Benzyl-1-oxo-1H-phthalazin-2-yl)acetylamino]-propionylamino-alkanoates 7a-c were synthesized from corresponding hydrazide 2-(4-Benzyl-1-oxo-1H-phthalazin-2-yl)-N-(2hydrazinocarbonyl-ethyl)-acetamide $3 \mathbf{b}$ as shown in scheme 4. 

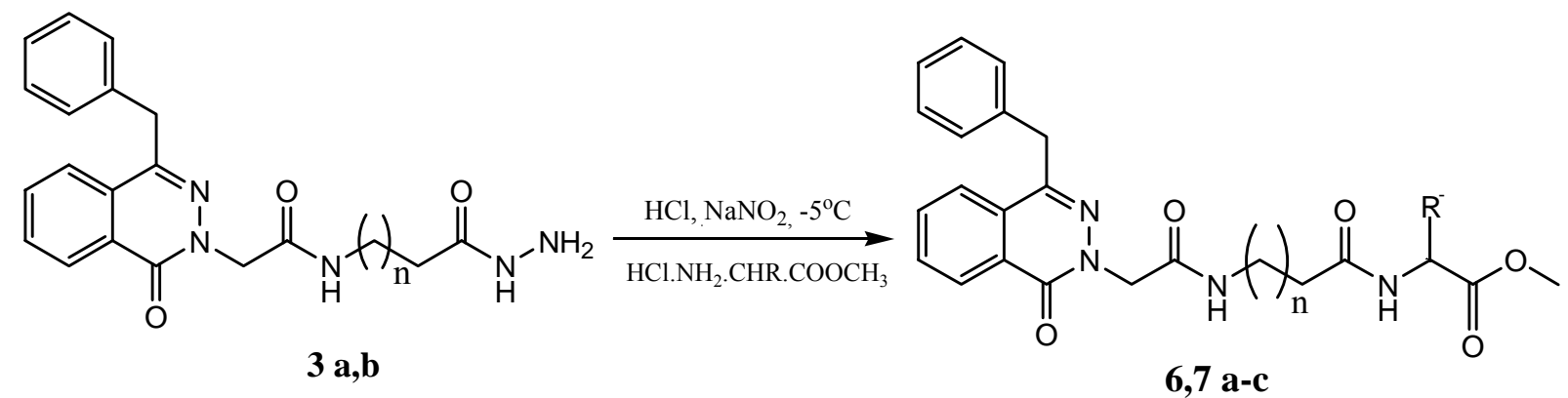

\begin{tabular}{c|c|c|c|c|c}
$\mathbf{6}$ & $\mathbf{n}$ & $\mathbf{R}$ & $\mathbf{7}$ & $\mathbf{n}$ & $\mathbf{R}$ \\
\hline $\mathbf{a}$ & $\mathbf{0}$ & $\mathbf{H}$ & $\mathbf{a}$ & $\mathbf{1}$ & $\mathbf{H}$ \\
\hline $\mathbf{b}$ & $\mathbf{0}$ & $\mathbf{H}-\mathbf{C H}_{2}$ & $\mathbf{b}$ & $\mathbf{1}$ & $\mathbf{H}-\mathbf{C H}_{2}$ \\
\hline $\mathbf{c}$ & $\mathbf{0}$ & $\begin{array}{c}\mathbf{C H}_{3}-\mathbf{C H}- \\
\mathbf{C H}_{3}\end{array}$ & $\mathbf{c}$ & $\mathbf{1}$ & $\mathbf{\mathbf { C H } _ { 3 } - \mathbf { C H } -}$ \\
$\mathbf{C} \mathbf{H}_{3}$
\end{tabular}

Scheme 4: Synthesis of dipeptide derivatives 6,7a-c.

\section{References}

1- C. Avendano, J.C. Men_endez, Medicinal Chemistry of Anticancer Drugs, First ed., Elsevier, 2008, p. 1 (Chapter 1).

2- El-Rayes, S., Gomaa, M.S.,Abouelmagd, A., Fathalla, W., Ali, I.A.I.Synthesis and antiproliferative assay of triazolyl-2,2-dimethyl-3phenylpropanoates as potential HDAC inhibitors RSC Advances 2019, 9(24), 13896.

3- S. M. El Rayes,A. Abo Elmagd,Gomaa M. S., Ibrahim A. I. Ali, Walid Fathalla, Faheem Hyder Pottoo,F. A. KhanConvenient synthesis and antiproliferative activity of methyl 2-[3-(3-phenyl-quinoxalin-2ylsulfanyl)propanamido] alkanoates and N-Alkyl 3-((3-phenylquinoxalin-2yl)sulfanyl) propanamides accepted in ACS Omega 2019 DOI 10.1021/acsomega.9b02320 
4- Demirayak S, Karaburun AC, Beis R. Some pyrrole substituted aryl pyridazinone and phthalazinone derivatives and their antihypertensive activities. Eur. J. Med. Chem., 2004, 39, 10891095.

5- Munín J, Santana L, Uriarte Eu, Borges F, Quezada E. A comparative synthesis of 6-benzyl 2,3-dihydroimidazo[2,1-a]phthalazine and 2H-7benzyl-3,4-dihydropyrimido[2,1-a]phthalazine. Tetrahedron Lett., 2015, 56, $828-830$.

6- Nomoto Y, Obase H, Takai TH, Teranishi M, Nakamura J, Kubo K. Studies on cardiotonic agents. II. Synthesis of novel phthalazine and 1,2,3benzotriazine derivatives. Chem. Pharm. Bull. 1990, 38, 2179-2183.

7- Grasso S, De Sarro G, De Sarro A, Micale N, Zappalà M, Puja G, Baraldi M, De Micheli C. Synthesis and anticonvulsant activity of novel and potent 6,7-methylenedioxyphthalazin-1(2H)-ones. J. Med.Chem., 2000, 43, 28512859.

8- Sivakumar R, Kishore Guanasam S, Ramachandran S, Leonard JT. Pharmacological evaluation of some new 1-substituted-4hydroxyphthalazines. Eur. J. Med. Chem., 2002, 37, 793-801.

9- Madhavan GR, Chakrabarti R, Kumar SKB, Misra P, Mamidi RNVS, Balraju V, Kasiram K, Babu RK, Suresh J, Lohray BB, Lohrayb VB, Iqbal J, Rajagopalan R. Novel phthalazinone and benzoxazinone containing thiazolidinediones as antidiabetic and hypolipidemic agents. Eur. J. Med. Chem., 2001, 36, 627-637.

10- Lenz EM, Wilson LD, Wright B, Partridge EA, Rodgers CT, Haycock PR, Lindon JC, Nicholson JK. A comparison of quantitative NMR and radiolabelling studies of the metabolism and excretion of Statil (3-(4-bromo2-fluorobenzyl)-4-oxo-3H-phthalazin-1-ylacetic acid) in the rat. J. Pharm. Biomed. Anal., 2002, 28, 31-43. 
11- Johensen M, Rehse K, Pertz H, Stasch JP, Bischoff E. New antithrombotic 1 phthalazinamines with serotonin antagonistic properties.Arch. Pharm., 2003, 336, 591-597.

12- Pramanik A. Synthesis of biologically important phthalazinones, 2,3benzoxazin-1-ones and isoindolinones from ninhydrin and their antimicrobial activity. Tetrahedron Lett., 2013, 54, 3137-3143.

13-Shetgiri NP, Nayak BK. Synthesis and antimicrobial activities of oxadiazoles, phthalazines and indolinones. Indian J. Chem., 2005, 44B, $1267-1272$.

14- Cockcroft X, Dillon KJ, Dixon L, Drzewiecki J, Kerrigan F, Loh VM Jr, Martin NMB, Menear KA, Smith GCM. Phthalazinones 2: Optimisation and synthesis of novel potent inhibitors of poly(ADPribose) polymerase. Bioorg. Med. Chem. Lett., 2006, 16, 1040-1044.

15-Loh VM Jr, Cockcroft X, Dillon KJ, Dixon L, Drzewiecki J, Eversley PJ, Gomez S, Hoare J, Kerrigan F, Matthews IT, Menear KA, Martin NM, Newton RF, Paul J, Smith GC, Vile J, Whittle AJ. Phthalazinones. Part 1: The design and synthesis of a novel series of potent inhibitors of poly(ADPribose)polymerase. Bioorg. Med. Chem. Lett., 2005, 15, 2235-2238.

16-Eldehna WM, Ibrahim HS, Abdel-Aziz HA, Farrag NN, Youssef MM. Design, synthesis and in vitro antitumor activity of novel Nsubstituted- 4phenyl/benzylphthalazin-1-ones. Eur. J. Med. Chem., 2015, 89, 549-560.

17-Haider N, Kabicher T, Käferböck J, Plenk A. Synthesis and in-vitro antitumor activity of 1-[3-(indol-1-yl)prop-1-yn-1-yl]phthalazines and related compounds. Molecules, 2007, 12, 1900-1909.

18- Kim JS, Lee HJ, Suh ME, Choo HY, Lee SK, Park HJ, Kim C, Park SW, Lee CO. Synthesis and cytotoxicity of 1-substituted 2-methyl- 1H- 
imidazo[4,5-g]phthalazine-4,9-dione derivatives. Bioorg. Med. Chem., 2004, $12,3683-3686$.

19- I.H. Hall, E.S. Hall, O.T. Wong, Anti Cancer Drugs 3 (1992) 55e62.

20- I.H. Hall, D.W. Covington, J.R. Wheaton, R.A. Izydore, X. Zhou, Pharmazie 2001, 56, 168-174.

21-V.M. Loh，X.-1. Cockcroft, K.J. Dillon， L. Dixon，J. Drzewiecki，P.J. Eversley, S. Gomez, J. Hoare, F. Kerrigan, I.T.W. Matthews, K.A. Menear, N.M.B. Martin, R.F. Newton, J. Paul, G.C.M. Smith, J. Vilec, A.J. Whittlec, Bioorg. Med. Chem. Lett. 2005, 15, 2235-2238.

22-X.L. Cockcroft, K.J. Dillon, L. Dixon, J. Drzewiecki, F. Kerrigan, V.M. Loh, N.M.B. Martin, K.A. Menear, G.C.M. Smith, Bioorg. Med. Chem. Lett. 2006, 16, 1040-1044.

23-K.A. Menear, C. Adcock, R. Boulter, X.-1. Cockcroft, L. Copsey, A. Cranston, K.J. Dillon, J. Drzewiecki, S. Garman, S. Gomez, H. Javaid, F. Kerrigan, C. Knights, A. Lau, V.M. Loh, I.T.W. Matthews, S. Moore, M.J. O'Connor, G.C.M. Smith, N.M.B. Martin, J. Med. Chem. 2008, 51, 65816591.

24- Prime M.E., Courtney S.M., Brookfield F.A, Marston R.W., Walker V., Warne J., Boyd A.E., Kairies N.A., von der Saal W., Limberg A., Georges G., Engh R.A., Goller B., Rueger P., Rueth M. Phthalazinone pyrazoles as potent, selective, and orally bioavailable inhibitors of aurora-A kinase. $J$. Med. Chem., 2011, 54, 312-319 ().

25-Organic Syntheses, Coll., 1943, 2, 61; 1933, 13, 10

26-El-Wahab AHFA, Mohamed HM, El-Agrody AM, El-Nassag MA, Bedair AH. Synthesis and biological screening of 4-benzyl-2Hphthalazine derivatives. Pharmaceuticals, 2011, 4, 1158-1170 
27- Marzouk.M.I; Shaker.S.A; Abdel Hafiz.A.A\& et al: Design and Synthesis of New Phthalazinone Derivatives Containing Benzyl Moiety with Anticipated Antitumor Activity, Biol. Pharm. Bull.: 2016, 39, 239-251.

28- Ibrahim. A. I. Ali, Walid Fathalla, S. M. El Rayes Convenient syntheses of methyl 2-[2-(3-acetyl-4-methyl-2-oxo-1,2-dihydroquinolin-1-yl)acetamido] alkanoates and their O-regioisomers ARKIVOC 2008 (xiii) 179-188

29- S. M. El Rayes Convenient synthesis of some methyl-N-[2-(3-oxo-6-p-tolyl2,3,4,5-tetrahydropyridazin-2-yl)-acetylamino]amino acid esters ARKIVOC 2008 (xvi) 243-254

30- S. M. El Rayes Convenient Synthesis and Antimicrobial Activity of Some Novel Amino Acid Coupled Triazoles Molecules 2010, 15, 6759-6772; doi:10.3390/molecules 15106759

31- Walid Fathalla, S. M. El Rayes, Ibrahim A. I. Ali Convenient synthesis of 1substituted-4-methyl-5-oxo $\quad[1,2,4]$ triazolo[4,3-a]quinazolines $\quad$ ARKIVOC 2007 (xvi) 173-186

32- Hofmann, K.; Thompson, T. A.; Yajima, H.; Schwarts, E. T.; Enouye, H. J. Am. Chem. Soc. 1960, 82, 3715.

33-Ali. I.A. , Fathallah. W. \& Elrayes.S.M.; 2008: Convenient syntheses of methyl 2-[2-(3-acetyl-4-methyl-2-oxo-1,2-dihydroquinolin-1-yl)acetamido] alkanoates and their O-regioisomers, ARKIVOC (xiii) 179-188.

34- Eldehna W.M. , Ibrahim H.S. , Abdel-Aziz H.A. \& et al ;: Design, synthesis and in vitro antitumor activity of novel N-substituted-4phenyl/benzylphthalazin-1-ones , European Journal of Medicinal Chemistry 2015, (89), 549-560.

35-Elrayes.S.M, ; Ali. I.A. \& Fathallah. W;; Convenient Synthesis of Some Novel Pyridazinone Bearing Triazole Moieties, Journal of Heterocyclic Chemistry : 2019, 56, 51, DOI: 10.1002/3369. 